\title{
ARTHROSCOPY UNDER LOCAL ANAESTHESIA USING CONTROLLED PRESSURE-IRRIGATION WITH PRILOCAINE
}

\author{
TORSTEN WREDMARK, ROLF LUNDH
}

\begin{abstract}
From the Department of Orthopaedic Surgery and the Department of Anaesthesiology, Karolinska Institute, Huddinge University Hospital
\end{abstract}

\begin{abstract}
One hundred and seventy-four consecutive patients with symptoms of internal derangement of the knee were examined with an arthroscope under local anaesthesia using a continuous pressure-irrigation system. A 0.2 per cent prilocaine-saline solution was used as irrigation fluid. In the first 19 patients the serum level of prilocaine was monitored for six hours after the start of irrigation. Eighteen of the 174 patients had a transcutaneous partial meniscectomy at the same time as the examination.

All the patients tolerated the examination well. The distension of the knee produced by the pressureirrigation system provided a high degree of diagnostic accuracy. The serum levels of prilocaine were low throughout the monitoring period reaching a mean peak value of 0.28 micrograms per millilitre after one hour. There were no adverse side-effects. This technique provides a safe and efficient method to meet the increasing demands of arthroscopic procedures of the knee.
\end{abstract}

Since the pioneering work of Takagi in Japan much has been written on the role of arthroscopy in the diagnosis of derangements of the knee. Nowadays, with the help of endoscopy, diagnostic accuracy has improved considerably. Several arthroscopic techniques have.been reported which use different approaches to the knee. The most common is the lateral approach, while others favour the central approach through the patellar tendon (Gillquist and Hagberg 1976). Arthroscopic examination can be carried out under local anaesthesia (Jonsson and Becker 1976; McGinty and Matza 1978; Eriksson, personal communication). Most of the early techniques of local anaesthesia used lidocaine or bupivacaine in single instillations. Different methods of controlled pressure-irrigation have been used previously; Halperin et al. (1978) used a pneumatic tourniquet around a plastic bag containing saline solution connected to the arthroscope and Gillquist and Hagberg (1976) used a blood pump to control the speed and pressure of the irrigation. However, the serum levels of local anaesthetics used have not, to our knowledge, been published, although there is one report of the serum levels taken 30 minutes after an intra-articular bolus injection of 50 milligrams of bupivacaine (Eriksson, personal communication). The purpose of this paper is to show the synovial absorption of the anaesthetic and to report a modified technique of local anaesthesia in arthroscopy of the knee.

\section{MATERIAL AND METHODS}

One hundred and seventy-four consecutive patients referred to us with symptoms of internal derangement of the knee were examined with an arthroscope. The age of the patients ranged from 16 to 61 years with an average of 32.9 years. There were 125 men and 49 women. The patients received no premedication. The examinations were performed with a 5.0 millimetre Stortz arthroscope using the central approach under strict aseptic conditions. Under local anaesthesia the suprapatellar pouch was punctured with a fenestrated cannula and distended with a 0.2 per cent prilocaine-saline solution. Irrigation and distension of the knee were maintained by a pneumatic tourniquet around the plastic bag containing the anaesthetic-saline solution which was later connected to the arthroscope. The pressure was usually around 150 millimetres of mercury, the drainage being passive through the cannula. The patients flexed their knees a couple of times to get used to the tension of the joint. The skin and the patellar tendon were infiltrated with five millilitres of a one per cent prilocaine-adrenaline solution and the arthroscope was then introduced into the joint. In 18 patients a transcutaneous partial meniscectomy was also performed, adding a few more millilitres of one per cent prilocaine-adrenaline solution at the second site of puncture before introducing the surgical instrument; a bloodless field was not used.

T. Wredmark, MD, Associate Professor, Department of Orthopaedic Surgery

R. Lundh, MD, Senior Registrar, Department of Anaesthesiology

Karolinska Institute, Huddinge University Hospital, S-141 86 Huddinge, Sweden.

Requests for reprints should be sent to Dr T. Wredmark.

(C) 1982 British Editorial Society of Bone and Joint Surgery 0301-620X/82/5113-0583\$2.00 
In the later part of the study the procedure was somewhat altered. The arthroscope was introduced at the lateral edge of the patellar tendon at the level of the inferior pole of the patella after local infiltration of the skin and synovium with a one per cent solution of prilocaine-adrenaline. The joint was distended with the anaesthetic solution through the arthroscope. Drainage was not used routinely but if visibility was poor a drainage cannula was introduced in the suprapatellar pouch.

In the first 19 patients the serum level of prilocaine was monitored for six hours with blood samples being taken from the arm at intervals of 5, 15, 30, 60, 120, 240 and 360 minutes after intra-articular instillation had been started. The concentration of prilocaine in the serum was measured by selective ion monitoring by Astra Läkemedel, Södertälje, Sweden. The sensitivity of the monitoring system for the first nine patients was \pm 0.02 micrograms per millilitre and two nanograms per millilitre for the remaining 10 patients. The amount of anaesthetic solution used and the period of irrigation were registered.

\section{RESULTS}

The diagnostic findings for all the patients are given in Table I. The mean irrigation time for the first 19 patients was 18 minutes with a range from 11 to 44 minutes and the mean amount of irrigation fluid remaining in the knee was 66 millilitres, with a range of 0 to 325 millilitres.

Table I. Diagnostic findings in arthroscopy of 174 patients

\begin{tabular}{|lr|}
\hline Medial meniscus & 11 \\
Bucket-handle tears & 24 \\
Parrot-beak tears & 10 \\
Horizontal tears & \\
Lateral meniscus & 2 \\
$\quad$ Bucket-handle tears & 11 \\
Parrot-beak tears & 5 \\
Horizontal tears & 21 \\
Chondromalacia & 14 \\
Synovitis & 19 \\
Osteoarthritis & 13 \\
Rupture of the anterior cruciate ligament & 1 \\
Rupture of the posterior cruciate ligament & 23 \\
Miscellaneous & 20 \\
No intra-articular abnormality & \\
\hline
\end{tabular}

The initial five-minute serum levels were very low in 16 patients, rising rapidly to a mean maximum of 0.28 micrograms per millilitre (range 0.12 to 0.68 micrograms per millilitre) after one hour. They then gradually decreased. The mean serum concentrations of prilocaine ( \pm the standard error) for these 16 patients are given in Figure 1. In one patient 325 millilitres of prilocaine were accidentally administered to the periarticular soft tissues and the patient was therefore excluded from the study although the serum levels followed the same pattern as in the other patients with a peak value ( 2.8 micrograms per millilitre) after one hour and then gradually diminishing with time.

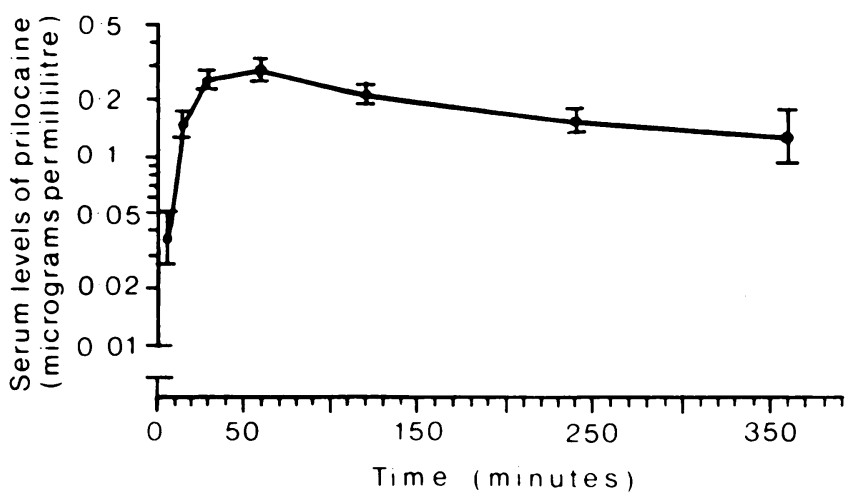

Fig. 1

The mean serum concentration and the standard error of the mean with time. This calculation is based on 16 patients only, as three patients with very high serum levels have been excluded.

Two patients whose initial serum levels of prilocaine were approximately 10 times the average of the other patients, 2.55 and 2.53 micrograms per millilitre, were also excluded. Although inadvertent intravenous administration during the procedure cannot be excluded, prilocaine levels such as these are not to be expected. Another possible explanation might be if the patients had a high level of $\alpha$-glucoproteins which bind local anaesthetic agents. However, if this was the case the serum levels should only increase by approximately five times and stay on a high level throughout the whole time of sampling. In our study, however, the values rapidly fell to near normal after 30 minutes.

\section{DISCUSSION}

Local anaesthesia is very useful for diagnostic arthroscopy in patients with derangement of the knee and can also be used in operations under arthroscopic control. The use of local anaesthesia as opposed to general or spinal anaesthesia has several advantages. An anaesthetist is not required and, as the management of the patient after the procedure is minimal, arthroscopic examination can be carried out on outpatients. All the patients in our study tolerated the procedure well and none required supplementary medication. In no case did the examination have to be abandoned because of discomfort. We found no limitations in diagnostic accuracy due to the anaesthetic technique. On the contrary, the controlled pressure-irrigation with anaesthetic allowed an extremely good dilatation of the joint and thereby the visualisation of all the structures.

Lidocaine and bupivacaine have previously been used to irrigate the knee during arthroscopy (Halperin $e t$ 
al. 1978). The toxicity of a local anaesthetic is dependent on its concentration in the blood, which in turn depends on its absorption from the site of injection or application, its distribution throughout the tissues of the body and its degradation. As we were not sure of the absorption from the synovium, we chose a local anaesthetic with low systemic toxicity, prilocaine. Eriksson et al. (1966) showed that the systemic toxicity of prilocaine is less than that of lidocaine, probably because it is metabolised more rapidly.

Plasma concentrations producing toxic symptoms differ between different local anaesthetics. Mild toxic symptoms may occur with plasma concentrations exceeding five micrograms per millilitre of prilocaine or lidocaine compared with one or two micrograms per millilitre with bupivacaine (Foldes et al. 1965). Variations in individual patients may however occur (Scott 1975).

The maximal concentration of prilocaine in the plasma in our series was 2.8 micrograms per millilitre (due to accidental irrigation of periarticular soft tissue) which is a normal plasma level during epidural anaesthesia, and below the toxic level of five micrograms per millilitre. An important consideration concerning the use of high doses of prilocaine (600 milligrams) is the formation of methaemoglobin (Scott, Owen and Rich- mond 1964). Methaemoglobinaemia causes cyanosis by decreasing the oxygen carrying capability of iron in the red blood cells. The cyanosis is not relieved by the administration of oxygen but can be treated by intravenous administration of methylene blue. The presence of methaemoglobin in concentrations of up to one per cent of the total haemoglobin is physiologically normal as it is formed continuously and is promptly reduced to haemoglobin. Methaemoglobin must exceed 20 per cent of the total haemoglobin to produce clinical symptoms (Crawford 1965). Crawford (1965) measured levels of prilocaine in the blood and methaemoglobin levels simultaneously and found that methaemoglobin reached a peak value of 7.5 per cent of the total haemoglobin with a peak level of 4.1 micrograms per millilitre of prilocaine in the blood. Although we did not measure levels of methaemoglobin in our study, the concentration of prilocaine in the blood was too low to produce any clinically significant methaemoglobinaemia. In no case did we see any cyanosis or any other complications pertaining to the local anaesthetic.

We conclude that this technique of controlled pressure-irrigation using prilocaine is a safe, well tolerated and useful method of local anaesthesia for arthroscopic procedures in the knee.

\section{REFERENCES}

Crawford OB. Methemoglobin in man following the use of prilocaine. Acta Anaesthesiol Scand 1965;Suppl 16:183-7.

Eriksson E, Englesson S, Wahlqvist S, Örtengren B. Study of the intravenous toxicity in man and some in vitro studies on the distribution and adsorbability. Acta Chir Scand 1966:Suppl 358:25-36.

Eriksson E. Prilocaine : an experimental study in man of a new local anaesthetic with special regards to efficacy, toxicity and excretion. Acta Chir Scand 1966:Suppl 358.

Foldes FF, Davidson GM, Duncalf D, Kuwabara S. The intravenous toxicity of local anesthetic agents in man. Clin Pharmacol Ther 1965;6: 32835 .

Gillquist J, Hagberg G. A new modification of the technique of arthroscopy of the knee joint. Acta Chir Scand 1976:142:123-30.

Halperin N, Axer A, Hirschberg E, Agasi M. Arthroscopy of the knee under local anesthesia and controlled pressure-irrigation. Clin Orthop 1978:134:176 9

Jonsson L, Becker RL. Arthroscopy, technique and role of the assistant. Orthop Rer 1976;9:31-43.

McGinty JB, Matza RA. Arthroscopy of the knee. J Bone Joint Surg [ Am] 1978;60-A:787-9.

Scott DB. Evaluation of clinical tolerance of local anaesthetic agents. Br J Anaesth 1975;47 Suppl :328-31.

Scott DB, Owen JA, Richmond J. Methaemoglobinaemia due to prilocaine. Lancet 1964;ii:728-9. 